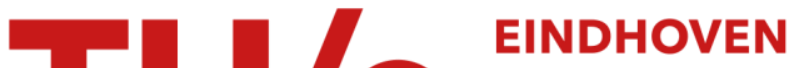 \\ UNIVERSITY OF \\ TECHNOLOGY
}

\section{Scaling quantum-dot light-emitting diodes to submicrometer sizes}

Citation for published version (APA):

Fiore, A., Chen, J. X., \& llegems, M. (2002). Scaling quantum-dot light-emitting diodes to submicrometer sizes. Applied Physics Letters, 81(10), 1756-1758. https://doi.org/10.1063/1.1504880

DOI:

$10.1063 / 1.1504880$

Document status and date:

Published: 01/01/2002

Document Version:

Publisher's PDF, also known as Version of Record (includes final page, issue and volume numbers)

Please check the document version of this publication:

- A submitted manuscript is the version of the article upon submission and before peer-review. There can be important differences between the submitted version and the official published version of record. People interested in the research are advised to contact the author for the final version of the publication, or visit the $\mathrm{DOI}$ to the publisher's website.

- The final author version and the galley proof are versions of the publication after peer review.

- The final published version features the final layout of the paper including the volume, issue and page numbers.

Link to publication

\section{General rights}

Copyright and moral rights for the publications made accessible in the public portal are retained by the authors and/or other copyright owners and it is a condition of accessing publications that users recognise and abide by the legal requirements associated with these rights.

- Users may download and print one copy of any publication from the public portal for the purpose of private study or research.

- You may not further distribute the material or use it for any profit-making activity or commercial gain

- You may freely distribute the URL identifying the publication in the public portal.

If the publication is distributed under the terms of Article $25 \mathrm{fa}$ of the Dutch Copyright Act, indicated by the "Taverne" license above, please follow below link for the End User Agreement:

www.tue.nl/taverne

Take down policy

If you believe that this document breaches copyright please contact us at:

openaccess@tue.nl

providing details and we will investigate your claim. 


\title{
Scaling quantum-dot light-emitting diodes to submicrometer sizes
}

\author{
A. Fiore ${ }^{a)}$ \\ Institute of Quantum Electronics and Photonics, Ecole Polytechnique Fédérale de Lausanne, \\ CH-1015 Lausanne, Switzerland and Institute of Photonics and Nanotechnology, CNR, \\ via del Cineto Romano 42, 00156 Roma, Italy \\ J. X. Chen ${ }^{\text {b) }}$ and M. Ilegems \\ Institute of Quantum Electronics and Photonics, Ecole Polytechnique Fédérale de Lausanne, \\ CH-1015 Lausanne, Switzerland
}

(Received 2 May 2002; accepted for publication 10 July 2002)

\begin{abstract}
We introduce a device structure and a fabrication technique that allow the realization of efficient light-emitting diodes (LEDs) with dimensions of the active area in the $\approx 100 \mathrm{~nm}$ range. Using optical lithography, selective oxidation, and an active region consisting of InAs quantum dots (QDs), we fabricated LEDs with light-current-voltage characteristics which scale well with nominal device area down to $600 \mathrm{~nm}$ diam at room temperature. The scaling behavior provides evidence for strong carrier confinement in the QDs and shows the potential for the realization of high-efficiency single-photon LEDs operating at room temperature. (C) 2002 American Institute of Physics. [DOI: 10.1063/1.1504880]
\end{abstract}

Device size scaling is the subject of major research interest, in optoelectronics as in electronics. For some applications, high efficiency from a light-emitting device (laser, LED) is needed at low current levels. Since high efficiency is usually reached at a given current density, this requires reducing the device area, i.e., scaling down the device. Moreover, efficient coupling to single-mode fibers requires small active areas (in the few micrometer range). Examples of scaling issues are found in edge-emitting lasers for optical communication in single-mode fibers, $980 \mathrm{~nm}$ pump lasers for fiber amplifiers, and low-threshold vertical-cavity surfaceemitting lasers (VCSELs). Recently, a further stimulus towards the realization of ultrasmall optical devices is coming from the field of quantum communication and quantum computing based on semiconductor nanostructures. As an example, efficient and compact single-photon emitters might be realized from single semiconductor quantum dots (QDs), ${ }^{1-4}$ if a way is found to isolate and efficiently inject current into a single QD. While antibunching in electrically pumped single QDs has been very recently demonstrated, ${ }^{5}$ the device structure adopted in that case, which is based on postfiltering of emitted photons rather than selective injection, is not suitable for a high-efficiency single-photon emitter. If the active material is constituted by self-assembled QDs, which typically have areal densities in the $10^{8}-10^{11} \mathrm{~cm}^{-2}$ range, the active device size should be well below $1 \mu \mathrm{m}$ in order to contain a single QD, which represents a formidable task for both device design and fabrication. Three major problems are faced when one tries to scale down the device size while keeping good efficiency. First, if etching through the active region is used to define the active area, nonradiative recombination at etched sidewalls strongly reduces the efficiency as the perimeter/area ratio increases. Second, if a current-

\footnotetext{
${ }^{a)}$ Electronic mail: andrea.fiore @epfl.ch

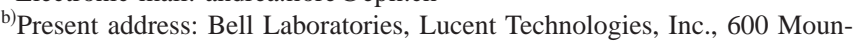
tain Ave., Murray Hill, NJ 07974.
}

blocking layer is used to define a current aperture near the active region (e.g., $\mathrm{Al}_{2} \mathrm{O}_{3}$ obtained by selective oxidation of AlGaAs in VCSELs), current spreading between the blocking layer and the active region can increase the effective active diameter by several micrometers. ${ }^{6-8}$ Finally, carrier diffusion in the active region [usually quantum wells (QWs)] increases the effective radius by the diffusion length, typically, $1-2 \mu \mathrm{m}$. While current spreading can be minimized by proper design of the injection region, carrier diffusion can be suppressed only by applying a lateral carrier confinement in the active region. Several approaches have been reported, such as QW interdiffusion, ${ }^{9}$ segmented QWs, ${ }^{10}$ and selfassembled QDs, ${ }^{11}$ although with limited success, probably due to the need to combine strong carrier confinement and good radiative properties of the active material.

In this letter, we propose an approach to the realization of ultrasmall light-emitting devices with active areas well below $1 \mu \mathrm{m}^{2}$, which relies on three points: (a) Fabrication of current apertures in the $\approx 100 \mathrm{~nm}$ range using standard optical lithography, selective oxidation of AlGaAs and selfaligned contact definition; (b) optimized current injection in the active region using a graded-band-gap hole injector; and (c) suppression of lateral carrier diffusion by the use of selfassembled QDs with deep three-dimensional (3D) confinement potential. Using this approach, we demonstrate QD LEDs with characteristics that scale well with nominal size down to $600 \mathrm{~nm}$ at room temperature (RT), showing that lateral current spreading and carrier diffusion are effectively suppressed even at RT. This could open the way to highperformance, ultrasmall QD-based LEDs and VCSELs, and ultimately high-efficiency single-photon LEDs.

Bottom-emitting microcavity LEDs with a single layer of self-assembled QDs were grown by molecular beam epitaxy on $n$-doped (001) GaAs substrates [see the sketch in Fig. 1(a)]. The bottom mirror consists of a 3.5 period $n$-doped $\mathrm{GaAs} / \mathrm{Al}_{0.9} \mathrm{Ga}_{0.1} \mathrm{As}$ quarter-wave stack. The cavity is made of $20 \mathrm{~nm} n-\mathrm{Al}_{0.3} \mathrm{Ga}_{0.7} \mathrm{As}, 114 \mathrm{~nm} n$-GaAs, $45 \mathrm{~nm}$ 


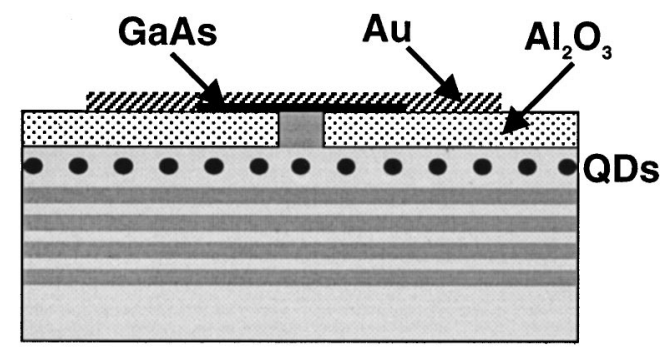

(a)

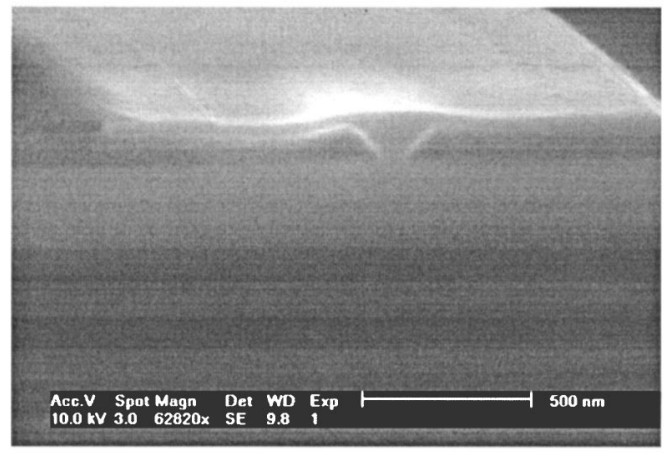

(b)

FIG. 1. (a) Schematics of the fabricated LED structure. (b) Cross-sectional SEM image of a $70 \mathrm{~nm}$ aperture obtained by lateral oxidation from a $1-\mu \mathrm{m}-$ wide stripe.

undoped GaAs, a layer of QDs, and $45 \mathrm{~nm}$ undoped GaAs. The QDs are grown by continuously depositing 2.9 ML of InAs and covering with a 5-nm-thick $\operatorname{In}_{0.15} \mathrm{Ga}_{0.85}$ As layer to redshift the emission to the $1.3 \mu \mathrm{m}$ region. These growth conditions produce QDs with $25 \mathrm{~nm}$ diam and $7 \mathrm{~nm}$ height, providing a strong RT photoluminescence peak at $1300 \mathrm{~nm}$, with a full width at half maximum $(\mathrm{FWHM})=45 \mathrm{~nm} .{ }^{12}$ As compared to short-wavelength $(\approx 1000 \mathrm{~nm})$ QDs, these dots have a larger potential barrier to carrier escape from the dot ground state to the wetting layer [the difference in transition energies is $\approx 300 \mathrm{meV}$ (Ref. 13) as compared to $\approx 100 \mathrm{meV}$ for short-wavelength QDs (Ref. 14)]. On top of the cavity, a hole injector is grown, consisting of a 32-nm-undoped graded-band-gap region with $\mathrm{Al}$ composition linearly increasing from $0 \%$ to $85 \%$, and a $135 \mathrm{~nm} \mathrm{Al}_{0.85} \mathrm{Ga}_{0.15}$ As current aperture to be oxidized. The bottom $20 \mathrm{~nm}$ in the $\mathrm{Al}_{0.85} \mathrm{Ga}_{0.15} \mathrm{As}$ layer are undoped, while the rest is $p$ doped $\left(p=2 \times 10^{18} \mathrm{~cm}^{-3}\right)$. The structure is capped by a heavily doped GaAs $p$-contact layer. The injector is designed so as to facilitate vertical hole transport from the $\mathrm{Al}_{0.85} \mathrm{Ga}_{0.15} \mathrm{As}$ aperture region to the QDs by avoiding potential steps at heterointerfaces in the valence band and by providing a potential gradient directed towards the active layer. The doping profile was also found to be critical.

Device processing starts with the definition of shallow mesas of variable diameter $(1-30 \mu \mathrm{m})$ by optical lithography and wet etching of the top GaAs cap layer. The exposed $\mathrm{Al}_{0.85} \mathrm{Ga}_{0.15} \mathrm{As}$ is then oxidized selectively by heating the sample at $400^{\circ} \mathrm{C}$ for $55 \mathrm{~min}$ in a $\mathrm{H}_{2} \mathrm{O}$ atmosphere created by bubbling $\mathrm{N}_{2}$ in a water bath at $85^{\circ} \mathrm{C}$. The oxidation starts at the exposed surface and then penetrates laterally under the GaAs cap layer, thus defining a current aperture whose diameter can be controlled down to around $100 \mathrm{~nm}$ by varying Downloaded 08 Oct 2009 to 131.155.151.77. Redistribution subject
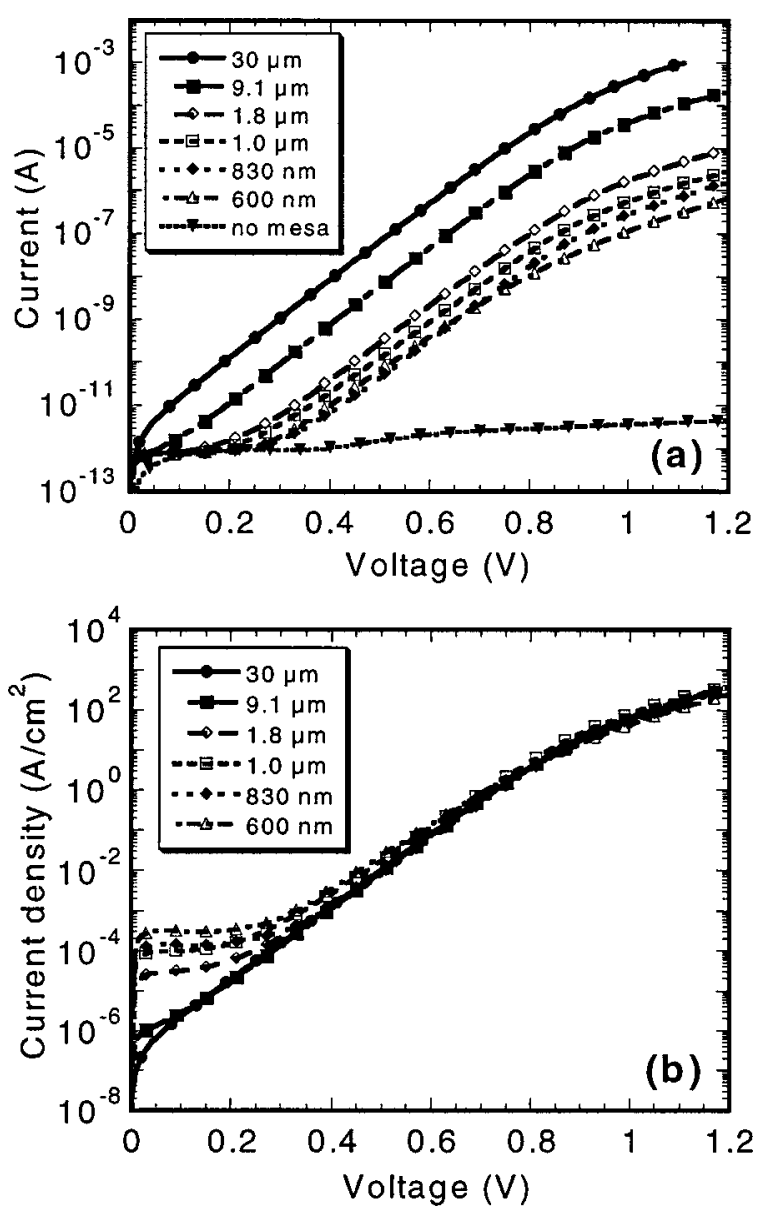

FIG. 2. (a) Room-temperature current-voltage characteristics of QD LEDs with current aperture diameters ranging from $30 \mu \mathrm{m}$ to $600 \mathrm{~nm}$ ("no mesa:" control device with no current aperture). (b) Current density vs voltage curves for the same devices, calculated using the unoxidized aperture areas measured by SEM.

the oxidation time. Figure 1(b) shows a scanning-electron microscope (SEM) image of an aperture of $70 \mathrm{~nm}$ defined in this way. Broad-area $p$ contacts $\left(3.8 \times 10^{-5} \mathrm{~cm}^{2}\right)$ are then evaporated on top of the mesas, with uncritical alignment, and an $n$ contact is evaporated on the substrate side. Because the surface of the sample, outside of the mesas, is covered with an insulating $\mathrm{Al}_{2} \mathrm{O}_{3}$ oxide, current is forced to flow into the small current apertures. The key point which allows the definition of $\ll 1 \mu \mathrm{m}$ current apertures with such a simple procedure is the simultaneous and self-aligned definition of the current aperture and of a contact-defining oxide by means of the vertical-lateral oxidation of $\mathrm{AlGaAs}$, as first proposed in Ref. 15. In contrast to previously reported approaches, 5,16 this allows us to fabricate devices with active diameters down to $100 \mathrm{~nm}$ by optical lithography.

Figure 2(a) shows the RT current versus voltage characteristics (measured in a two-probe setup) for current-aperture diameters ranging from $30 \mu \mathrm{m}$ to $600 \mathrm{~nm}$. The $I-V$ curve of a control device with no mesa (i.e., metal on oxide) is also shown for comparison. The curves can be fitted with the exponential diode characteristics (ideality factor $n \approx 2$ ) over five to six orders of magnitude. At low bias $(V<0.3 \mathrm{~V})$, leakage through the broad-area oxide prevails over current flowing into the mesas for the smallest devices. Note that the leakage current density through the oxide is very low for the entire bias range investigated (maximum $\approx 10^{-7} \mathrm{~A} / \mathrm{cm}^{2}$ at o AIP license or copyright; see http://apl.aip.org/apl/copyright.jsp 


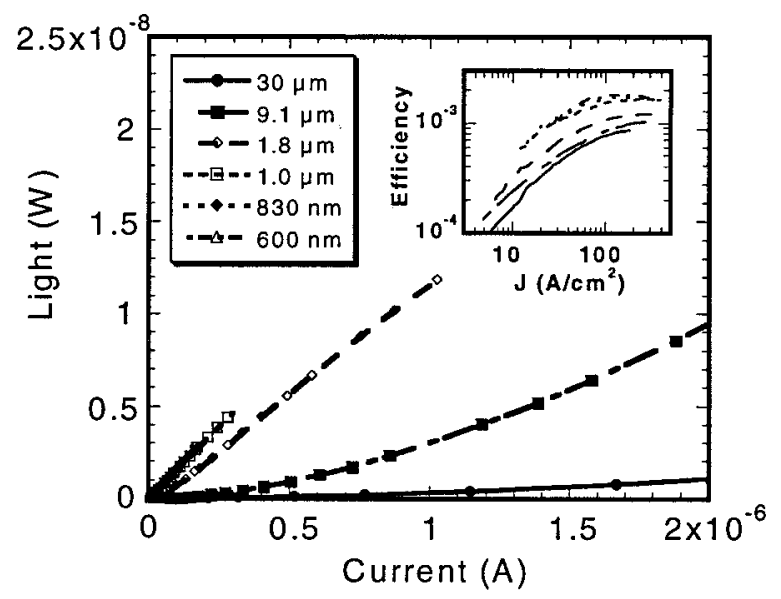

FIG. 3. Room-temperature light-current characteristics of QD LEDs. The $L-I$ curves of devices with diameters of $1.0 \mu \mathrm{m}, 830 \mathrm{~nm}$, and $600 \mathrm{~nm}$ are almost superposed, hence, hardly distinguishable. Inset: external quantum efficiency vs current density.

$1.2 \mathrm{~V})$. At high bias, the device resistance results in a departure from the ideal diode behavior. Figure 2(b) shows the current densities, calculated using the unoxidized aperture areas measured by SEM before evaporating the contacts, i.e., assuming no lateral carrier leakage. Remarkably, the curves superpose very well, particularly in the on-region of the diode $(V>0.6 \mathrm{~V})$. From the overlap among the different $J-V$ curves, we can estimate that the lateral diffusion/spreading length is well below $100 \mathrm{~nm}$ in the on-region. This proves that all carrier leakage paths (current spreading, carrier diffusion, and nonradiative recombination) are effectively suppressed in these structures. Some leakage is still seen at low bias (apparent current density larger for smaller devices, which implies an effective injection area larger than measured by SEM), which can be attributed to current spreading below the oxide at very high diode impedances.

In order to further confirm these conclusions, we investigated the efficiency in these ultrasmall LEDs. The lightcurrent $(L-I)$ characteristics at room temperature are shown in Fig. 3. In the low current range shown, large devices have very poor efficiency and nonlinear $L-I$ characteristics, which is an indication of predominant nonradiative recombination at very low current density, a common feature in LEDs. In contrast, small devices have linear $L-I$ curves and higher efficiency, because they operate at the optimum current density, which is around $100 \mathrm{~A} / \mathrm{cm}^{2}$ in this sample. It should be noticed that efficiency is not reduced even for the smallest devices of $600 \mathrm{~nm}$ diam. This proves that the oxide aperture does not introduce defects in the active region, which would systematically degrade the perfomance as the area is reduced. Also, by plotting the efficiency as a function of current density (inset of Fig. 3) we find good scaling behavior and similar peak efficiency for diameters ranging from $30 \mu \mathrm{m}$ to $600 \mathrm{~nm}$, which further confirm the negligible lateral carrier leakage. We found that the efficiency fluctuates considerably among nominally identical devices for diameters around and below $600 \mathrm{~nm}$, some showing efficiencies even larger than broad-area devices (for this reason LEDs with diameters below $600 \mathrm{~nm}$ are not presented here). This may be attributed to growth-related nonradiative defects with areal density in the $10^{8} \mathrm{~cm}^{-2}$ range, so that a small and variable number of them is present in the active area of submicrometer devices. The presence of defects is also confirmed by the relatively low peak external quantum efficiency of $0.1 \%$ measured in large $(400 \mu \mathrm{m})$ devices, even with no oxide aperturing, as compared to efficiencies of over $1 \%$ measured by us ${ }^{13}$ in similar QD structures.

In conclusion, we have presented an approach towards the scaling of light-emitting devices to submicrometer sizes. By combining a simple self-aligned fabrication technique with an optimized design of the epitaxial structure, it is possible to realize devices with active areas well below $1 \mu \mathrm{m}^{2}$ while keeping a constant efficiency. Scaling of $I-V$ and $L-I$ curves with nominal device area demonstrates that strong carrier 3D confinement in QDs results in a reduced diffusion length $<100 \mathrm{~nm}$ even at room temperature. As it is clear from the light-current characteristics shown in Fig. 3, when low output powers are needed, small-scaled devices are more efficient than large devices which operate at much smaller current densities. The strong carrier confinement in QDs may be applied to the fabrication of submicrometer-sized lasers with ultrasmall threshold currents and of single-QD LEDs for single-photon applications.

The authors wish to thank Dr. R. P. Stanley (CSEM Neuchàtel) for many interesting discussions, and Professor C. Weisbuch (Ecole Polytechnique, Palaiseau) for stimulating this work. Financial support from the European Commission through the fifth framework IST program and from the Swiss National Science Foundation is acknowledged.

${ }^{1}$ O. Benson, C. Santori, M. Pelton, and Y. Yamamoto, Phys. Rev. Lett. 84, 2513 (2000).

${ }^{2}$ P. Michler, A. Imamoglu, M. D. Mason, P. J. Carson, G. F. Strouse, and S. K. Buratto, Nature (London) 406, 968 (2000).

${ }^{3}$ P. Michler, A. Kiraz, C. Becher, W. V. Schoenfeld, P. M. Petroff, L. Zhang, E. Hu, and A. Imamoglu, Science 290, 2282 (2000).

${ }^{4}$ C. Santori, M. Pelton, G. Solomon, Y. Dale, and Y. Yamamoto, Phys. Rev. Lett. 86, 1502 (2001).

${ }^{5}$ Z. Yuan, B. E. Kardynal, R. M. Stevenson, A. J. Shields, C. J. Lobo, K. Cooper, N. S. Beattie, D. A. Ritchie, and M. Pepper, Science 295, 102 (2002)

${ }^{6}$ N. K. Dutta, J. Appl. Phys. 68, 1961 (1990).

${ }^{7}$ G. M. Yang, M. H. MacDougal, and P. D. Dapkus, J. Appl. Phys. 80, 4837 (1996).

${ }^{8}$ E. R. Hegblom, N. M. Margalit, A. Fiore, and L. A. Coldren, IEEE J. Sel. Top. Quantum Electron. 5, 553 (1999).

${ }^{9}$ R. L. Naone, P. D. Floyd, D. B. Young, E. R. Hegblom, T. A. Strand, and L. A. Coldren, IEEE J. Sel. Top. Quantum Electron. 4, 706 (1998).

${ }^{10}$ T. A. Strand, B. J. Thibeault, and L. A. Coldren, J. Appl. Phys. 81, 3377 (1997).

${ }^{11}$ J. K. Kim, R. L. Naone, and L. A. Coldren, IEEE J. Sel. Top. Quantum Electron. 6, 504 (2000).

${ }^{12}$ A. Fiore, U. Oesterle, R. P. Stanley, R. Houdré, F. Lelarge, M. Ilegems, P. Borri, W. Langbein, D. Birkedal, J. M. Hvam, M. Cantoni, and F. Bobard, IEEE J. Quantum Electron. 37, 1050 (2001).

${ }^{13}$ A. Fiore, U. Oesterle, R. P. Stanley, and M. Ilegems, IEEE Photonics Technol. Lett. 12, 1601 (2000).

${ }^{14}$ D. Bimberg, N. Kirstaedter, N. N. Ledentsov, Z. I. Alferov, P. S. Kop'ev, and V. M. Ustinov, IEEE J. Sel. Top. Quantum Electron. 3, 196 (1997).

${ }^{15}$ F. A. Kish, S. J. Caracci, J. N. Holonyak, J. M. Dallesasse, K. C. Hsieh, S. C. Smith, and R. D. Burnham, Appl. Phys. Lett. 59, 1755 (1991).

${ }^{16}$ H. Chen, Z. Zou, C. Cao, and D. G. Deppe, Appl. Phys. Lett. 80, 350 (2002) 